\title{
Molding the nascent corporate social responsibility agenda in Singapore: of pragmatism, soft regulation, and the economic imperative
}

\author{
Eugene K. B. Tan
}

Received: 28 June 2012 / Accepted: 9 October 2012 / Published online: 13 November 2012

(C) Springer Science+Business Media Dordrecht 2012

\begin{abstract}
This paper seeks to examine the putative growth of corporate social responsibility (CSR) in Singapore. A key impetus for the nascent CSR movement in twenty-first century Singapore is the economic imperative. As a trade-dependent industrializing economy, the economic development drive coupled with the need for international expansion has made it necessary for Singapore businesses to be cognizant of the growing CSR movement in the western, industrialized world. The government supports the CSR endeavour with an instrumental bent, where CSR ideas and concepts are adapted, incorporated, and promoted in various sectors of the economy. This paper assesses the state's active encouragement of CSR in various facets of economic life in Singapore. The government sees itself as a promoter and practitioner of CSR. For instance, Singapore's unique tripartite labor relations have recently emphasized a CSR gloss while CSR is also touted as being beneficial for corporate governance as well as improving the competitiveness of companies and improving the quality of life. However, CSR is too often seen as another form of corporate governance. This paper argues that the CSR drive in Singapore coheres with the government's pragmatic approach to governance broadly conceived. There are many intrinsic and tangible benefits in the government being seen as an active promoter of CSR in various facets of Singapore life. The close association with the various concerns of CSR ensures that the government is seen to be involved in issues, such as environmentalism, work-life balance, anticorruption, and philanthropy, that concern and appeal to the younger generation of Singaporeans. The CSR endorsement by the state, while not taking a legislative framework and still very much a private sector-driven initiative, is in accord with Singapore's political and cultural values where the promotion of social responsibility (individual and group), harmony, cohesion, and stability in a multi-racial, multireligious, and multi-lingual society are very much valued. In studying the putative CSR movement in Singapore, a sense of the values that the state, in partnership with the business world, hopes to inculcate would be evident.
\end{abstract}

E. K. B. Tan $(\bowtie)$

School of Law, Singapore Management University, 50 Stamford Road, Singapore 178899, Singapore e-mail: eugene@smu.edu.sg 
Keywords Corporate social responsibility · Regulation · Government · Singapore · Drivers of CSR

While corporate social responsibility (CSR) is not new in Asia or Singapore, the understanding and importance of CSR has grown in tandem with developments in Europe and North America (see also Montgomery 2005; Welford 2004). CSR has acquired renewed vigor in the corporate landscape in Asia in which the notion of corporate credibility, linked with how a company conducts its business and makes profits, is of growing importance (e.g., Frynas 2006; International Herald Tribune, 25 October 2006). More recently, several Asian countries, including Indonesia and Malaysia, have enacted legislation requiring local and foreign companies to behave responsibly (Chhabara 2007; The Straits Times Singapore 2007a, b, c; Lyon 2007; Nguyen 2007).

Not surprisingly, as an important economic node, CSR has gained a fledgling, if ambivalent, prominence in Singapore in the last few years. Yet there has not been any rigorous debate and understanding of CSR in the Singapore context (see also Lim-Lum 2004). As the government is a significant player in Singapore's economy, it is perhaps not all surprising that it has taken on the role as a promoter and practitioner of CSR, although this is motivated by concerns of making Singapore a business-friendly hub. Hence, despite the lack of conceptual clarity, the CSR scene has acquired tentative relevancy, prominence, and awareness.

A key impetus for the nascent CSR movement in Singapore is the economic imperative. As a trade-dependent industrializing economy, the economic development drive coupled with the need for international expansion has made it necessary for Singapore businesses to be cognizant of the growing CSR movement in the industrialized world. The government supports the CSR endeavor with an instrumental bent, implicitly recognizing that CSR has the potential to engender economic vitality and productivity through innovation, enterprise, competition, skills, and investment. However, CSR awareness does not necessarily translate to resolve and action in imbibing CSR as an integral part of doing business.

The Singapore approach to CSR and its top-down development is a hybrid model in which the putative CSR movement is government-led through quasi-government organizations. This ensures that the government maintains significant influence, if not control and authority, over how CSR is perceived, promoted, and regulated. At the same time, there is significant cooperation with the other key stakeholders viz the employers and the trade union movement. This cooperative partnership approach ensures that the CSR movement is neither overly regulated nor heavily enforcementbased. Instead, this multi-sectoral collaborative partnership reinforces the buy-in and mutual cooperation in the development of the putative movement while maintaining the avowed national goal of keeping Singapore business friendly. This hybrid model incorporates significant flexibility in which the stakeholders of the CSR movement have the autonomy to pursue their various objectives under the CSR umbrella without undue concern that the CSR climate is becoming contentious. This is achieved by the government setting the norm and tone for the development of CSR.

The essay is organized as follows. The first part outlines the contemporary state of CSR in Singapore. The second part focuses on the operating paradigm for CSR in 
Singapore through an examination of the tripartite model and the use of CSR as a mode of regulation through norms. The concerns of the policy ideals of a harmonious society and CSR as a strategic differentiator are also discussed. The third part of the essay examines the imperatives driving the CSR scene in Singapore viz CSR as a driver of innovation and competitiveness as well as concerns with CSR as a potential trade barrier. Singapore's response to climate change is considered in this regard. The essay then concludes with some final observations.

\section{State of play of CSR in Singapore}

In a recent study on CSR reporting in seven Asian countries, Chapple and Moon (2005: p. 437) noted Singapore's relatively low level of CSR penetration despite it having the highest levels of economic and social development among the sampled countries (India, Indonesia, Malaysia, the Philippines, Singapore, South Korea, and Thailand). They opined that the Singapore government's heavy investment in areas such as education and environmental protection has removed "the need and stimulus for Singaporean companies to do so themselves." The relatively large tax base, its economic success, and its small geographical area (with no significant agriculture sector) may provide empirical evidence that wealth dilutes the CSR imperatives. Yet, the Singapore experience cannot be generalizable since countries such as the USA, UK, and Japan have higher tax bases and relatively high CSR penetration. In this regard, it can be said that while awareness of CSR is high among businesses and corporate executives in Singapore, that does not necessarily lead to a similar level of engagement with CSR. This was confirmed in a national survey on CSR conducted in 2008 (see discussion in Tan 2011). This performance gap is not all that unusual given the lack of institutionalization of CSR in Singapore's socioeconomic and political landscape as well as the competing understanding and perceptions of CSR encouraged in Singapore (see also Sriramesh et al. 2007).

While the government has been tacitly supportive of CSR, it should be noted that CSR has a somewhat ambivalent, if not patchy, presence in Singapore. Indeed, CSR is construed as an omnibus term that covers many aspects of business activities and its relations with society. It has become a catch-phrase justifying the need for business to be involved in a variety of social activities and causes. As a junior Minister noted of the Singapore situation, "There are various stakeholders advocating different areas of CSR. For example, NTUC advocates CSR from a workers' perspective while the Consumers Association of Singapore (CASE) promotes CSR from a consumer protection perspective. The Singapore National Employers and business federations (SNEF and SBF) and other chambers actively promote various CSR-related programs to their members. The Ministry of Finance and the Monetary Authority of Singapore advocate CSR from a corporate governance perspective" (Foo 2004). Clearly, CSR is interpreted in a fairly all-encompassing manner given its contemporary importance and it being supportive of the various imperatives and policy initiatives at the national level. Beyond traditional and ubiquitous corporate philanthropy and corporate volunteerism, CSR has been spoken of and invoked in issues pertaining to corporate governance, environmental protection, public relations, community engagement and social cohesion, labor issues, and Singapore's reputation as a trusted business hub. 
In May 2004, with the government's implicit blessings, the National Tripartite Initiative on CSR (NTI on CSR) was established as a national steering committee to "embrace CSR as a coordinated national initiative - to view the issues holistically and address any gaps at the national level" (Foo 2004). The NTI on CSR includes key stakeholders from the business sector, unions, and the government including key stakeholders like the National Volunteer and Philanthropy Centre, Consumers Association of Singapore, Singapore National Cooperative Federation, Singapore Institute of Directors, and relevant government ministries and agencies. The NTI on CSR went on to found the national CSR society known as the Singapore Compact for Corporate Social Responsibility (Singapore Compact) in January 2005. The tripartite system is replicated in Singapore Compact, which is officially constituted as "a platform in (sic) fostering dialogue and collaboration among various CSR stakeholders." The society seeks to play "a pivotal role in defining the direction and landscape of CSR in Singapore, and help Singapore embrace CSR as a coordinated national initiative." It also provides a forum for collaboration, support, and sharing of information and good CSR practices, and serves to facilitate the implementation and promotion of CSR through the establishment of sectoral networks or other appropriate groupings. This tripartite initiative aims to also provide strategic direction and overall co-ordination of the various CSR programs, including helping small and medium enterprises adopt good CSR practices. $^{2}$

Given the government's interest in CSR for a variety of policy objectives, CSR certainly has a growing presence in Singapore even as the profile is noteworthy for its absence of any thoughtful debate on the scope and implications of CSR for business and its stakeholders. As corporate activity is very much organized and structured along Anglo-American lines, it is not surprising that an Anglo-American understanding of CSR holds sway. Nevertheless, the stance in Singapore is to evolve its understanding and practice of CSR grounded in the local context and needs.

How has the government understood CSR? There is neither a significant ministerial statement nor an official government policy statement on CSR. What we have are some pronouncements from Singapore's junior echelon of Ministers on what CSR is:

Simply defined, CSR is about a corporation's 'social licence to operate'. This licence is not granted based merely on financial considerations. It is, in effect, an unwritten social contract. Unless a company earns that licence, and maintains it on the basis of trust, there will ultimately be negative commercial implications. Consumers and employees will vote with their feet. Financial bottom lines are therefore no longer the only meaningful indicators of market success. ... CSR has therefore become more than an exercise in corporate communications and traditional philanthropy. It is no longer simply about handing out money and sitting back. Adopting a structured approach to align business operations with social values is fast becoming an indispensable

\footnotetext{
${ }^{1}$ See Singapore Compact website, http://www.csrsingapore.org/aboutus.php (accessed 8 October 2012).

${ }^{2}$ For Singapore Compact's terms of reference and activities, see its website at http://www.csrsingapore.org/. Earlier in April 2003, an independent nonprofit organization, the Centre for CSR, was formed with the aim of "improving standards of ethical and responsible behavior within the community in general and among corporations in particular." This entity is now defunct.
} 
principle of corporate management and an invaluable business strategy. (Balakrishnan 2004)

The business of companies is to make money. But there are many ways of making money. Some practices help individuals, societies, and countries grow and develop. Other practices exploit and debilitate the workforce and degrade the environment. CSR is about doing good even as companies seek to do well. It is about showing that the two goals are complementary rather than contradictory. (Heng 2005a)

What is evident is that CSR is conceived as a sound business approach that helps companies make money while doing good. Leveraging on the social contract idea, CSR is also perceived to embody the symbiotic relationship between businesses and their wider operating environment. Interestingly, this is very much in line with the communitarian ethos espoused by Singapore's political leadership. Such a philosophy is also in sync with Singapore's conception as a stakeholder society.

Even as sociopolitical and cultural norms are relied upon to buttress the relevance of CSR in various facets of Singapore life, the push for CSR in Singapore, however, has been dominated by the business case for CSR. There is the need to widen the generally narrow conception of CSR in Singapore which tends to focus on corporate philanthropy and volunteerism, and one-off community projects. Given the growing global footprint of Singapore's business and economic activities, this need to widen the conception of CSR arises on two fronts. First, the promotion of CSR understanding and action has to incorporate "global corporate social responsibility" in which companies are responsible for their actions beyond their boundaries to include the supply chains (Davis et al. 2008). Secondly, CSR has to engage the very issues that arise from doing business such as discrimination, labor, social, sustainability, and corruption that are endemic in much of Asia.

\section{The contours of CSR in Singapore}

Tripartite and consensual approach

In seeking to review and formulate broad CSR strategies, Singapore has opted for the tripartite approach to promote CSR. This tripartite system was initially adopted to manage the combative industrial relations in Singapore during the politically turbulent and economically uncertain 1960s. This successful governance system, undergirded by the core values of consensus, consultation, and an acute aversion to confrontation, has evolved and is now the bedrock of Singapore's economic life. ${ }^{3}$ The three key stakeholders are the trade unions, government, and employers. The employers are represented by the Singapore National Employers Federation as well as the Singapore Business Federation. The trade unions are represented by the umbrella body known as the National Trades Union Congress (NTUC), a movement that is symbiotically and closely linked with Singapore's ruling

\footnotetext{
${ }_{3}^{3}$ A useful primer on tripartism Singapore style is Tan (2007). See also Leggett (2007) and references cited therein.
} 
People's Action Party. ${ }^{4}$ The government is represented by the Ministry of Manpower and relevant statutory boards.

As mentioned earlier, Singapore Compact functions as a national CSR body to formulate a coordinated strategy and bring about synergy among the stakeholders. Thus, from the outset, the tenor and mission of the officially endorsed CSR movement is premised on a collaborative partnership involving the key stakeholders of business, unions, and the government. Such an organizational setup suggests that the pace and texture of the CSR movement in Singapore will be co-determined resulting in broader socioeconomic interests taking precedence over particular special interests. What is noteworthy is that the tripartite core setup was assiduously maintained and welded onto its founding ethos even as the organization is organized and run as a civil society organization. ${ }^{5}$ This tripartite regime engenders a collaborationist mindset and sensitizes the stakeholders to the issues and challenges of CSR as posed to the different parties. Consequently, the CSR environment in Singapore is characterized by a lack of overt contention, a general reticence in pushing the CSR agenda, nonexistent employee activism, and wariness with excessive government regulation and enforcement.

In its short existence, the Singapore Compact has purposefully occupied the strategic middle ground and plays a pivotal role in defining the direction and landscape of CSR in Singapore. As the primary vehicle to consolidate and strengthen existing efforts as well as broaden the base for collaboration among CSR stakeholders in Singapore, Singapore Compact aims to develop strategies to promote and to strengthen existing CSR efforts in Singapore, organizes networking events, training and advisory programs, and information services. More crucially, Singapore Compact plays a critical and significant role in Singapore's ongoing attempts to define the meaning, ambit, and role of CSR in Singapore in order to help distinguish Singapore's CSR agenda and ethos from that found in Europe and North America. This, in turn, prevents external parties from dictating or defining what CSR could and should be in Singapore. The government has emphasized that CSR must be contextualized and developed in an autochthonous manner: "Consequently, while the government supports the concept of corporate social responsibility, we also believe that objective measures of CSR must be formulated, which are transparent internationally but based on local conditions after consultation with all stakeholders" (Balakrishnan 2004).

Given the potential for external influence in the molding of Singapore's CSR agenda, the government also seeks to influence the debate and development of CSR. It certainly does not want CSR to be a vehicle for contention between civil society and business as well as between business and government. There is certainly little appreciation for undue CSR activism on the part of NGOs and civil society. The goal ultimately is to make Singapore a business-friendly place without the hassle of such

\footnotetext{
${ }^{4}$ On the close PAP-NTUC ties, see People's Action Party (1999). See further the NTUC's perspective at http://www.ntucworld.org.sg/ntucunions/abt_ntuc_pap.asp \& http://www.ntucworld.org.sg/ntucunions/ abt_ntuc_tripartism.htm (accessed 26 December 2007). The Secretary-General of the NTUC has traditionally been a Cabinet Minister as well.

${ }^{5}$ See Singapore Compact (2007: p. 5) where tripartism is acknowledged as a cornerstone of the CSR scene in Singapore. See Singapore Compact's constitution at http://www.csrsingapore.org/files/SingaporeCompact-Constitution.PDF (last accessed 26 December 2007).
} 
issues hogging the limelight. What is also clear from the way the government has sought to manage the CSR movement is its preference for tripartism involving employers, unions, and government in a "many helping hands" approach. ${ }^{6}$ Taken together, such a mindset incorporates a notion of collective responsibility involving the relevant stakeholders. The role of the state is primarily to set out the policy framework, provide the infrastructure and resources necessary for the other sectors to play their part in the CSR movement.

\section{CSR as regulation}

Although the tripartite approach is the accepted norm in industrial relations and, now, in the CSR movement, it should be noted that the government's status in this corporatist setup is as primes inter pares. It does not need to assert itself strenuously under the tripartite approach but yet is able to exert its subtle influence and careful eye of the agenda. Such a light-touch approach, in essence, means that the government manages the pace of the development of the CSR scene in Singapore, mindful of the concerns, expectations of needs of the trade unions, employers, and society at large. At the outset, it can be said that the government sees itself as a promoter and practitioner of CSR. In elaborating this dual role, the government has outlined the triple benefits. First, the government can surface opportunities for which companies can reach out to the local community and stakeholders. Second, the government will publicly endorse and reward the efforts of socially responsible companies. ${ }^{7}$ Third, the government supports CSR by striving to be a good practitioner of its principles and thus sets the exemplar (Balakrishnan 2004).

In addition, governments can play a key role in standard setting even as CSR is about going beyond mere compliance, recognizing and urging companies to be mindful of their activities and impact on the wider operating environment. Governments can play a facilitative role in motivating companies to act voluntarily in raising the minimum standards of corporate conduct. Alternatively, they can set appropriate standards by providing a suitable policy and institutional environment through legislation, fiscal measures, and the endorsement of corporate social responsible conduct. ${ }^{8}$ The Singapore government recognizes that CSR can complement legislation by engendering the development of values and norms that promote principledriven compliance and regulation. Although the law is often the lowest common denominator and tends to lag behind developments in the social and business arenas, the government is sensitive to the severe limits of a "command-and-control" type regulatory framework in a subjective, and oftentimes, contentious area. The government is also not keen to have the CSR movement in Singapore developing into one

\footnotetext{
${ }^{6}$ This approach is primarily adopted in Singapore's delivery of social welfare services and support.

7 "Such public recognition will encourage other companies to adopt the principles of CSR in their day-today operations. This is because government endorsement not only enhances the reputation of the recognized company, but also heightens consumer awareness of CSR.” (Balakrishnan 2004) Two preexisting recognition schemes mentioned are the Singapore Quality Award and the Green Labeling Scheme.

${ }^{8}$ The British government is conscious of the importance of CSR to its foreign policy objectives and British international image where businesses are concerned. Indeed, the British government has been involved in promoting CSR in Singapore through sponsorship of CSR seminars and inviting British experts on CSR to speak to a Singaporean audience. On the role that governments can play, see Albareda et al. (2007).
} 
where the rights discourse is the primary prism of engagement. Rather, the preference is for engagement on the basis of accepted societal norms and dialogue premised on responsibilities of the different stakeholders.

What has so far characterized the Singaporean approach is one of a mix of minimal intervention at the policy front and a careful management of the perceptions of various interested parties in the CSR movement. Thus, regulation is minimal and no CSR-related legislation is in the works. Instead, the preferred approach is to make nuanced and targeted interventions that saliently highlight the growing importance of CSR while also ensuring that the overindulgent activism and confrontational aspects, features of CSR in advanced economies, are severely constrained. Even if regulation is seen as desirable, it is likely that the regulatory framework would be characterized by regulatory norms (rather than enshrined in mandatory laws) that have been arrived at in consultation with the other stakeholders ( $c f$. McBarnet et al. 2007). Ultimately, the policy intent is the same: To put the parties concerned on notice as to the expected corporate behavioral standards that are legitimately agreed upon, complied with voluntarily, and requiring minimal governmental oversight. The putative development of CSR in Singapore is one in which self-regulation by businesses is achieved through complementary mechanisms including industry norms, social and market forces at the domestic and international levels, and-to a lesser extent-legal accountability.

The intrinsic attraction of such an approach coheres around a norms-based, selfregulation appealing to the business sense of making profits in a sustainable, reputable, and equitable manner. This "carrot approach" also means that the government can wield the "stick" of legislation and regulation if earlier efforts to induce the desired conduct are unsuccessful. For instance, in labor relations, CSR has been recently emphasized in a variety of areas such as working conditions, work-life balance, and work health and safety conditions. This variegated application of CSR, away from the glare of collective bargaining arrangements, is presented as a winning formula for high performance at the workplace. In turn, this CSR gloss is also touted as being beneficial for corporate governance as well as improving the competitiveness of companies and improving the quality of life for employees. ${ }^{9}$

There are many intrinsic and tangible benefits in the government being an active promoter of CSR. The close association with the various concerns of CSR ensures that the government is seen to be involved in issues - such as environmentalism, work-life balance, anti-corruption, and philanthropy - that connect and appeal to the younger generation of Singaporeans. This is even so when business is not conceived as a long-term alternative to government, not least when there are no obvious public governance deficits in Singapore. In addition, by being a promoter and practitioner of $\mathrm{CSR}$, the government is asserting a leadership role through endorsing an equitable form of capitalism:

CSR is crucial for the achievement of sustainable and fair economic development. Governments, NGOs and management need to better appreciate the role of business in society. We need to work out innovative ways to be economically

\footnotetext{
${ }^{9}$ CSR has been the preferred vehicle to initiate organizational changes in Britain, see Deakin and Hobbs (2007).
} 
competitive, and yet fair to all stakeholders and to the environment. The free market does not have to be 'soul-less' capitalism. Thus, the government's twin roles as promoter and practitioner are particularly important in entrenching this attitude in corporations and the society at large. (Balakrishnan 2004)

By definition, CSR is not obligatory; the debate has centered on whether there is an expectation that businesses engage in CSR. The Singapore government is keen to adopt a non-regulatory approach in which compliance with voluntary standards is central. It is also keen to encourage multinational corporations as well as small and medium enterprises to engage in CSR more intensively and extensively. In both aspects, the government acts as a catalyst. As David Vogel (2005: p. 173) observes, "Civil and government regulation both have a legitimate role to play in improving public welfare. The former reflects the potential of the market for virtue; the latter recognizes its limits."

It remains to be seen how the role of the government will evolve in the years ahead in the development of the CSR agenda. What is clear, however, is that the Singapore government will need to adopt a "whole-of-government" approach given that CSR engages issues that are not strictly commercial/economic but also socio-cultural and political. Indeed, these issues have both a domestic and foreign audience as well, and the Singapore government is cautious in not allowing these issues to be a source of political mobilization and contention over the status quo. As such, policy coherence and integration are likely to be hallmarks of the Singapore bureaucracy in its management of the CSR agenda in Singapore.

\section{CSR and the harmonious society}

In Singapore, the government approaches CSR with a strategic inclination. Driven by pragmatism, the authorities are keen to make CSR work in Singapore's favor. Through the Singapore Compact, Singapore is plugged into the international network primarily through the United Nations Global Compact. At the local level, the manner in which CSR is promoted and practiced is in accord with Singapore's political and cultural values where the promotion of social responsibility (individual and group), harmony, cohesion, and stability in a multi-racial, multi-religious, and multi-lingual society are very much valued. The putative CSR movement in Singapore provides a sense of the values that the state, in partnership with the business world, hopes to inculcate. ${ }^{10}$ Indeed, while embracing the multiple stakeholders' concerns with CSR, the accent has been on constructing a sociopolitical and economic paradigm in which these concerns with CSR are seen as a vehicle for creating awareness, facilitating constructive deliberation, and enabling meaningful dialogue to arrive at a consensus. This means (as opposed to ends) approach to social construction consequently results in CSR being conceptually endowed as a mode of self-regulation, in sync with the currency of a voluntary, self-regulatory regime in Singapore.

\footnotetext{
${ }^{10}$ Another variant of harmony in governance is communist China's ideal of a "harmonious society" as a core, long-term policy planning objective. This objective accelerated with the "Building on a Harmonious Socialist Society" resolution at the sixth plenum of the 16th Central Committee of the Communist Party of China in October 2006. See http://news.xinhuanet.com/english/2006-10/11/content_5191071.htm
} 
CSR is portrayed as being facilitative of harmony in the business arena as well as in the relationship between business, government, and society. CSR, as seen from Singapore, encompasses philanthropy, corporate governance, as well as notions of equity and fairness in a trade- and investment-dependent economy that is extensively plugged into the international economic grid. By requiring businesses to take account of their economic, social, and environmental impacts, CSR is valued and promoted as being in accord with Singapore's political values wherein consensus and harmony are critical values. CSR is seen as a way of redressing some of the excesses of capitalism. Given that Singapore is a multi-racial, multi-religious, and multi-lingual society, CSR takes on a significant hue in employment and industrial relations (Lim 2004; see also Deakin and Whittaker 2007). This provides further impetus that CSR has to be contextualized to the local needs and the communitarian value system so valued in Singapore. ${ }^{11}$ Cultural relativism and a communitarian-based understanding of an individual rights and obligations vis-à-vis the society are distinctive features of the Singaporean communitarian approach towards governance. ${ }^{12}$

In such a consensus-seeking polity, the idea and ideal of harmony has an affinity with the Singapore government in its approach to governance. ${ }^{13}$ Here, harmony and consensus are pursued with a vengeance. ${ }^{14}$ One can discern a putative harmony ideology embedded in the CSR approach in Singapore, and this accords with the philosophy of social discipline that is cherished and inculcated consciously in Singaporean society. CSR provides the vital cog for business to play its part in contributing to the ideal of social harmony. All these benefits accrue without the need for excessive regulation and cost-incurring enforcement, both of which are likely to detract from the business of economic activity.

While there are no apparent governance deficits in Singapore society and business, the Singapore government has taken on an active interest in the CSR movement and its development as part of its larger interest in governance. Given that economic activity is of fundamental importance to Singapore's survival, corporate governance in the economic realm is critical, and CSR is viewed as an integral part of economic governance and part and parcel of the value creation process. In essence, the government finds it useful and important for it to be involved in the CSR movement. While its long-term strategy cannot be discerned with specificity at this fledgling stage, Jeremy Moon's observations

\footnotetext{
${ }^{11}$ On the communitarian ethos in Singapore, see Chua (1995).

${ }^{12}$ As then Prime Minister Lee Kuan Yew declared, "The basic difference in our approach springs from our traditional Asian value system which places the interests of the community over and above that of the individual." See Lee's speech at the opening of the Singapore Academy of Law, 31 August 1990.

13 Indeed, harmony and consensus are integral to Singapore's Shared Values. The five Shared Values are: (1) Nation before community and society above self; (2) Family as the basic unit of society; (3) Community support and respect for the individual; (4) Consensus, not conflict; and (5) Racial and religious harmony. The Shared Values can be likened to a national axiom of faith, a national ideology.

${ }^{14}$ Laura Nader's extensive work on dispute resolution systems provides useful insight into the notion of harmony ideology which "merges harmony and conflict" as part of the "hegemonic control system": Nader (1990: pp. 307-308). In Nader (2002: p. 32), she remarks that the harmony ideology places "an emphasis on conciliation, recognition that resolution of conflict is inherently good and that its reverse-continued conflict or controversy - is bad or dysfunctional, a view of harmonious behavior as more civilized than disputing behavior, the belief that consensus is of greater survival value than controversy. Harmony ideology can be powerful even when it contradicts the common realities of disputing."
} 
on CSR generally are apt: "CSR needs to be understood as part and parcel of a wider system of national societal governance incorporating government institutions, business organizations and non-governmental organizations" (Moon 2004: p. 1).

Notwithstanding the initial economic impetus, the non-economic benefits of and salutary effects of CSR accruing to Singaporean society is increasingly an attitudinal mindset that has its attractions where policy makers are concerned. Here sociocultural and political objectives exert a prominent influence on the promotion of CSR. A society with a preference for CSR, especially a series of practices agreed by the key stakeholders, conveys a picture of a harmonious place that is conducive to and facilitative of business operations and harmonious living. Besides, such a society would have less contention with energy and resources meaningfully channeled towards what is perceived as productive activity in the economic realm. CSR provides an alternative and more malleable face to the Singapore government's placing importance on the community, and a viable front to the consensus-seeking culture that is much encouraged in Singapore. In many respects, the government is once again drawing from its own positive experience in industrial relations where the abiding focus is on consensus, leading to industrial harmony and stability, for the common good.

\section{CSR as a strategic differentiator}

Further to the propagation of the harmony ideology, CSR is also portrayed as a feature of business activity that engenders distinct economic advantages. The notion and ideal of ethical leadership in the political realm as a key competitiveness instrument has been a key driver in Singapore's economic competitiveness. ${ }^{15}$ Ethical leadership, primarily manifested in Singapore's relatively corruption-free image, is promoted as an " $\mathrm{X}$ " factor' that is a "key differentiator" giving Singapore a competitive advantage (e.g., Lee 2005). This differentiator is now rigorously applied to the business sector where a CSR-enabled environment is seen as having the capacity to provide thought leadership in a society where the embracing of globalization is seen as vital for national survival. The then Secretary-General of the NTUC conceived of trade unions having a role in the formation of "ethical capitalism" which he defined as follows:

[A]t its heart [ethical capitalism] is not exploitative or adversarial, but collaborative and consensual, seeking to build wealth that is equitably shared, not amassed wealth for the privileged few'. The basic framework of ethical capitalism is a perspective based on common values, not adversarial relationships. Corporations serve stakeholders, not only shareholders.... Ethical capitalism is not an emasculated form of capitalism. It is robust, involving all stakeholders in responding to the challenges of

\footnotetext{
${ }^{15}$ See also Vietor (2007: chapter 3) on how the Singapore government creates the overall environment for "Singapore, Inc." successful competition in the global economy. The link between responsibility and a competitive economy has been affirmed in AccountAbility (2007). On the situation in Southeast Asia in this regard, see Anwar Ibrahim (2007).
} 
globalization such as the widening income disparities within and across nations. $^{16}$

This vision, commitment, and drive for ethical leadership is also manifested and marketed in the economic realm. This arises from the belief that the form of an ethical stance in the business world is a distinct competitive advantage (Heng 2005b; see also Richter and Mar 2004). This goes beyond CSR as a corporate communications tool and as a way of managing a company's reputation and operational risks. In this regard, Singapore is leveraging on its strengths of being a trusted brand in its quest to develop Singapore into a trusted business hub. The following lengthy quote from a senior Singapore bureaucrat is illustrative of this view (Heng 2005b):

At the national level, the benefit of good corporate governance and ethical behavior is quite clear. Singapore's strong reputation as a trustworthy jurisdiction is a key competitive advantage in attracting trade and investment, and in positioning Singapore as a premier financial center and business hub. When companies based here are associated with the values of integrity and credibility, they receive the recognition from global investors who are willing to pay a premium for their strong branding as trusted entities. Many companies, local and foreign, use Singapore as the home base to raise capital, to site command and control functions, and to engage in high-value R\&D and marketing functions. When companies, which are the basic building blocks of our economy, are associated with integrity and reliability, we all enjoy the spill-over effects of their good reputation. ... let me reiterate that Singapore's reputation as a trusted business hub gives us a competitive edge. It allows firms to differentiate themselves and to command a premium. This trust can be sustained and enhanced, if we deeply embed these in our system. Both external discipline and internal discipline are important. They are mutually reinforcing, creating a high norm of behavior. The benefits accrue to the company, as well as to the rest of the economy.

In this regard, Singapore is also cognizant of the tremendous opportunities in wealth management and transfer and philanthropy for its financial sector. Singapore believes that as more companies embrace CSR in the domestic setting, the more Singapore's reputation gets enhanced as a brand name for trust and reliability, in addition to its long-standing brands of efficiency and effectiveness.

\section{Imperatives driving CSR in Singapore}

Pragmatic virtue and the export markets

This essay argues that the CSR drive in Singapore coheres with the government's pragmatic approach to governance broadly conceived. The government recognizes that globalization has contributed to the rise and importance of CSR. Singapore's external trade is about four times the size of its domestic economy. With Singapore

${ }^{16} \operatorname{Lim}(2004):$ pp. 145-146) 
companies expanding overseas, in tandem with the state's efforts at consolidating the external wing of the economy, concerns with supply chains take on increasing importance. Besides, most of Singapore's products, in electronic, chemical, pharmaceutical products, are exported to the economies of the developed world where consumers in those markets have shown a greater appreciation for CSR. It would be fool-hardy for Singapore companies to be naïve or ignorant about the CSR agenda as part of their business strategies. Hence, the business driver acquires a significant profile in the government's encouragement of CSR. This was aptly put across by Lim (2005), then NTUC Secretary-General and Cabinet Minister: "CSR is also of concern to Singapore due to our position as a hub for international businesses and the international expansion plans of local companies and government linked companies. A lack of knowledge and management expertise in dealing with CSR issues may impede our development." In particular, given the government's cognizance of the centrality of CSR in the European business realm, CSR is increasingly viewed as a sine qua non and a source of competitive advantage for individual companies and the international competitiveness of Singapore:

The Singapore Government believes that properly crafted CSR initiatives would improve both the quality of life and the competitiveness of companies. ... Companies have grown to recognize that their continued prosperity is dependent upon the sustained viability of the community they operate in. Heng (2005a)

Similarly, greater consumer sophistication, awareness, and expectation, locally and overseas, have made CSR increasingly an issue Singapore companies cannot avoid nor ignore. CSR plays an important part in addressing the concerns, expectations, and demands of consumers, local and overseas, who increasingly expect companies to behave ethically and to be socially responsible. Corporate reputations can be undermined through a poor CSR approach and handling of such social drivers. It is also useful for the government to be involved in CSR as many issues under CSR are a concern to young Singaporeans, especially those born in the post-independence period, where post-material values and concerns take on a larger importance. ${ }^{17}$

The managerial conception of CSR is one perspective that is emphasized under the business case rubric for CSR. Given that Singapore is heavily dependent on the export trade, free trade is much valued and the government fears that protectionist sentiments globally (especially in the developed economies) may result in CSR requirements becoming a non-tariff trade barrier. As such, it is beneficial for Singapore companies to be mindful of CSR concerns when operating overseas, especially in the export of goods and services overseas, and the management of supply chains. In this regard, Singapore through the relevant government agency, SPRING Singapore, is closely following developments relating to the ISO 26000 guidance standard on social responsibility. The government has stated that it will "help to ensure that Singapore-based enterprises are aligned to any CSR standard which is adopted internationally. This in turn will ensure that Singapore's future trade flows are not hindered by technical barriers arising

\footnotetext{
${ }^{17}$ See Peh (2007). The ruling party's uniform is an all-white attire emphasizing purity and its commitment to clean governance.
} 
from international CSR standards" (Foo 2004). The potential impact on Singapore's companies from enhanced CSR requirements can be substantial considering that small and medium-sized enterprises (SMEs) make up $92 \%$ of all firms, account for employing two thirds of the workforce and generate $34 \%$ of the gross domestic product in Singapore. Thus, it comes as no surprise that SMEs are a constituency that the Singapore Compact and the government agencies hope to engage closely with vis-à-vis the CSR agenda.

CSR is also of concern to Singapore due to its position as a hub for international businesses and the international expansion plans of local companies and government-linked companies. A lack of knowledge and management expertise in dealing with CSR issues may impede Singapore's trade potential and development (Lim 2005). As European Union safety and health standards are enshrined in law, Singapore's exports are subjected to those legal requirements. These European standards have a "profound influence on manufacturing in Asia and beyond" (International Herald Tribune, 16 March 2007). In similar vein, as CSR increasingly embraces various social and political issues, concerns, and trends, it becomes imperative for companies to keep abreast of stakeholders' expectations. As a McKinsey report argues, "Companies must see the social and political dimensions not just as risks - areas for damage limitation-but also as opportunities" (Bonini et al. 2006: p. 21). Singapore seeks to tap the "first mover" advantage as we shall see in specific niches such as clean energy production. But this advantage is also conveyed in generating the brand perception that Singapore-based companies are CSR-enabled, giving weight to their relative competitiveness. While businesses have traditionally adhered to national standards, the trends point towards looking "beyond national boundaries to discover which standards to follow, and perhaps to exceed" (Davis et al. 2008: p. 34$).^{18}$

CSR as a catalyst and norm setter in governance initiatives

At a more local level, CSR is seen as a good segue to promote various government initiatives ranging from labor relations to climate change to the anti-terrorism efforts. In labor relations, for instance, wage restructuring and the enhancement of social safety nets are described as "good CSR practices and standards" (Lim 2005), even though the political imperatives behind them are more significant in light of a rapidly aging population and the rise of a significant income gap in Singaporean society. Painting these efforts as being in line with the CSR framework, Lim added that "labor movement aims to build a better life for workers through helping companies stay viable amidst the volatile business environment." What was left unsaid is that the government is cautious about the effectiveness of a legislative approach in managing change in a rapidly changing world. The preferred approach is for employees and employers to adapt to the changes voluntarily and to agree on the changes in a consensual manner. A similar approach can be discerned in Singapore's response to climate change.

\footnotetext{
${ }^{18}$ In this respect, it has been suggested that the European Union will lead in product environmental standards, the United States in corporate governance requirements, while international non-governmental organizations on human rights and labor rules (Davis et al. 2008: pp. 34-37).
} 
Singapore's attempt to ride on the climate change concerns suggests that the Singapore government is alive to the role that CSR can play within a multistakeholder approach. The developments suggest that responsibility in that realm can engender economic benefits arising from a commitment to innovation and competitiveness. Although Singapore is a non-Annex 1 signatory to the UN Framework Convention on Climate Change since 1997, it acceded to the Kyoto Protocol (the primary international agreement on climate change) in April 2006. ${ }^{19}$ The initial reservation with acceding to the Kyoto Protocol was over its ability to manage greenhouse gas emission levels in a manner that is not harmful to economic growth. However, in recent years accession has become viable with the tremendous potential demonstrated by Singapore companies in environmental technologies. Singapore plans to be a research and development hub for environmental and water-technology in Asia (MEWR 2006: p. 70). Here, we see the economic dictates apparently taking precedence over environmental and CSR concerns. ${ }^{20}$

Singapore's approach to climate change is instructive of the likely approach to CSR. While a detailed examination of Singapore's philosophy and management of climate change is outside the scope of this essay, the principles subscribed to by Singapore in this area are instructive of Singapore's reflexive approach to CSR. While cognizant of CSR as a virtue, the government is alive to CSR as political and economic imperatives. It is this resoluteness to seize the opportunity in light of prevailing global concerns that Singapore has wielded CSR as both a virtue and an imperative, alongside the opportunities for business and the Singapore brand name generally. Of note is how Singapore is seeking to capitalize on the alternative fuels and other environmentally friendly products as the next great "disruptive" technology. The developments following its accession to the Kyoto Protocol have been rapid and significant. In March 2007, the government announced that it was investing in research into the production of viable solar power. Capitalizing on Singapore's investments and commitment to science and technology as an engine of growth, Singapore is confident that it is well placed to occupy this niche, deliver the necessary innovation, and reap the economic dividends. It was reported that the seed money of SGD170 million "could result in an industry worth SGD1.7 billion and employing 7,000 people by 2015" (The Straits Times, 17 March 2007c). In April 2007, the government announced that it plans to develop Singapore as a center for research in environment sustainability "to develop knowledge and technologies for addressing global concerns.", 21

What is the role of CSR and how will it be deployed? Given the high profile concerns on climate change, biodiversity, environmental degradation, and sustainability, businesses will have to be more mindful and sensitive of their environmental

\footnotetext{
${ }^{19}$ Under the Kyoto Protocol, non-Annex I countries are not bound by emission reduction targets. Annex I countries are required to reduce the emissions of six greenhouse gases, on average, by $5.2 \%$ below 1990 levels during the first commitment period from 2008 to 2012.

${ }^{20}$ For an incisive and persuasive critique of Singapore's approach to the Kyoto Protocol, see Hamilton-Hart (2006).

${ }^{21}$ Press Release of the National Research Foundation, Prime Minister's Office, "Singapore set to become a centre for research in environmental sustainability," 20 April 2007. This press release was issued in Zurich, Switzerland. Lee Kuan Yew has also said that the environment will be a factor when immigrants decide where to go: see The Straits Times, 5 October 2007a.
} 
footprint. It is foreseeable that products and services will have to pass muster environmental standards, and companies held accountable for their environmental stewardship (or lack thereof). Furthermore, Singapore is heavily dependent on fossil fuels for its growing energy needs and is a key manufacturing hub that exports most of its products. ${ }^{22}$ In this potential threat regime to exportability, Singapore sees an opportunity to make significant inroads in its quest to be an innovation hub. ${ }^{23}$ As Thomas Friedman (The New York Times, 15 July2007) observes of green technology, "you can't make a product greener... without making it smartersmarter materials, smarter software or smarter design." Singapore's success in exploiting clean water technology has reaped economic dividends as well as increased self-sufficiency in meeting its need for water supplies. For Singapore, it believes that this success can be replicated in other areas related to the environment viz clean energy.

Again, Singapore is relying on another tripartite partnership - this time involving the public, private, and the people sectors in pushing for environmental sustainability. Using environmental sustainability as a prism and an independent variable, the response has been unabashedly pragmatic (The Straits Times, 12 May 2007b). First, the government has urged businesses of the need to rise up to the challenges of climate change and to commit themselves to pragmatic environmentalism. Second, it has signaled its commitment to promote clean energy research and grow the industry. It has also embarked on devising long-term strategies to help reduce Singapore's environmental footprint, but without imposing on itself undue restrictions on its economic growth. ${ }^{24}$ Third, it has emphasized its resolve that there is a trade-off in going green and that countries cannot be expected to go green for merely altruistic reasons. A universal approach that does not take into the diverse national circumstances is untenable for Singapore's policy makers. Economic growth cannot be sacrificed for green objectives. Hence, in the area of environment-related CSR concerns, the indications are already there for a moderate approach steering away from legislation but encouraging voluntary adoption of higher standards. In some respects, the accent is on a reflexive type of regulation, based on a learning process that is conscious of the balance and trade-offs between corporate interests and societal concerns, is apparent.

\section{Firms' response to CSR promotion effort}

Given the government's approach to CSR, it is perhaps not surprising that the firms' response to the developments in CSR globally and locally lacks urgency and remains lukewarm at best. This is perhaps not surprising as the government's efforts in promotion of CSR have been measured and preferring an educational approach. Much more needs to be done if Singapore is not to be disadvantaged by the growing importance of CSR internationally. The introduction of ISO 26000 guidance standard

\footnotetext{
${ }^{22}$ Chua Soon Guan, "Singapore committed to mitigating climate change," The Straits Times, 4 May 2007b, p. H12. Chua was then the Director of Strategic Policy at Singapore's Ministry of the Environment and Water Resources.

${ }^{23}$ Singapore's progress in the innovation arena is discussed in Kao (2007). See also Matten et al. (2007),

24 See generally Yaacob (2007).
} 
on social responsibility has upped the ante. The first national survey on CSR in 2008 revealed that the overall perception of CSR is somewhat dismal notwithstanding that Singapore is one of the more advanced Asian economies which is deeply plugged into the global economic grid. Among other things, the national CSR survey indicated a modest knowledge level and limited practice of CSR among Singapore-based business enterprises. Of the 507 enterprises surveyed, $60 \%$ were not aware of the term CSR. Among CSR-aware respondents, two thirds (or $27 \%$ of total respondents) have implemented CSR activities and one third have not (13\% of total respondents). At best, one can describe the CSR landscape in Singapore as immature, but with lots of room for development and growth. The survey findings suggest that Singapore-based businesses tended to view CSR as a compliance issue. This is a reactive approach to CSR, rather than one that seeks to promote positive change. ${ }^{25}$ Large enterprises, however, were twice as likely to be aware compared to SMEs. Foreign-owned enterprises were also more likely to be aware of CSR than their local-owned counterparts.

Although respondents were not surveyed on whether CSR can have a quasiregulatory dimension, there is a tentative recognition that CSR, if properly imbibed and practised by business entities, seeks to move resolutely beyond a compliance ("checking boxes") mindset to one which recognizes that effective CSR must have an ethical spine in which the dimensions of responsibility, transparency, and accountability are evident, recognised, and supported. In other words, the compliance mindset is still prevalent; the preferred mindset where the government is concerned is compliance as a means to the ends of effective corporate governance and ethical conduct. Furthermore, the issue is not whether Singaporean companies should engage in CSR but how to practice CSR in a meaningful manner. A pertinent consideration is the growing impact of international civil society, traditional media and new media, anti-globalization activists, and shareholder activism on matters of CSR.

Much as the Singapore government is alive to the possibility that CSR can be mainstreamed, the emphasis is on how society can encourage business to inject responsibility and wholesome values in their business activities. The question is not why engage in CSR, but how to ensure that CSR inculcates the appropriate corporate conduct while ensuring that profits that are made in the short term do not threaten long-term sustainability of the business and the economic ecosystem.

\section{Conclusion}

As an emerging global norm and with the proliferation of instruments for measuring different aspects CSR, CSR's potential impact on individuals, businesses, and countries is potentially significant in the years ahead (Tully 2005; Haslam 2007). It is likely that companies and countries that are able to leverage on society's concern with how business is done will reap benefits. With the government's tacit but strong backing, the fledgling CSR movement in Singapore seeks to remain ahead of the curve. In trying to have a handle on CSR as a putative global norm, Singapore is

\footnotetext{
${ }^{25}$ See also Saw Swee-Hock, Corporate Citizenship in Singapore (Singapore: Saw Centre for Financial Studies-NUS Business School, 2008) which focused on the state of corporate giving in Singapore.
} 
essentially taking a pre-emptive approach in gaining an understanding of the trends, changes, and implications where CSR is concerned.

This essay has tried to show that the government's promotion of CSR arises from the position that CSR makes economic and political sense in Singapore. In this regard, the top-down promotion of CSR in Singapore coheres with Moon's (2002) as analysis on why governments encourage CSR. CSR can substitute for government effort; it can complement government effort; and it can legitimize government policies. These reasons hold resonance in the Singapore context, especially with CSR complementing government efforts and legitimizing its various policies. Such a partnership approach enhances the efficiency and effectiveness of those efforts and policies. Even as CSR has a role as part of the government's preoccupation with governance systems, Singapore is still some way off from institutionalizing CSR, and CSR is not seen as a conduit for social change. Nevertheless, the role of the state and its passive encouragement of CSR are important because of its catalytic effect on the legitimacy of CSR as a facet of business life.

It is clear that the state does not encourage an overexuberant conception of CSR, opting instead for a more cautious, risk management approach to CSR. Given that CSR can impose business costs and envisages a robust civil society, the government is acutely aware of the double-edged sword of CSR and would be mindful of rightsizing the ambit of government, business, and societal relations vis-à-vis CSR. For the moment, the Government's approach is to encourage and highlight CSR best practices and engage in moral suasion. In the short term, the government may move to incentivize the adoption and reporting of CSR. It may also provide financial incentives. Much as centralized power of the state and a legalistic approach in governance are fundamental attributes in many facets of Singapore life, CSR in Singapore retains a distinctively non-legalistic ethos. The preference for the generation of norms, voluntary adoption of standards, and a subtle distrust of civil society remain important in considering how the CSR movement would evolve in the future. What is certain, however, is that it would take a light touch towards managing the CSR movement in the foreseeable future.

This essay argues that the Singaporean approach is characterized by the tripartite approach that emphasizes the four Cs of consultation, consensus, collaboration, and civility. A second feature is the enhancement of capacity building through Singapore Compact, the national CSR body which partners closely with the government, to enable Singapore to keep abreast of developments globally. Again, the hallmark of collaboration with local and foreign partners (in particular, the UN Global Compact) is evident. A third feature is the promotion of a low-level CSR conception among the stakeholders. A putative feature is the increasing attention shown to the possibility of developing as a CSR hub in which best practices and high ethical standards are leveraged upon to profile Singapore as an attractive place to do business especially when it relates to the business growing need for trust and integrity.

\section{References}

AccountAbility. (2007). The state of responsible competitiveness 2007. London: AccountAbility.

Albareda, L., Lozano, J. M., \& Ysa, T. (2007). Public policies on corporate social responsibility: the role of governments in Europe. Journal of Business Ethics, 74, 391-407. 
Anwar, I. (2007). 'Southeast Asia: fostering competitiveness through mutual accountability,' in The State of Responsible Competitiveness 2007 (London: AccountAbility), pp. 115-122.

Balakrishnan, V. (2004). 'Promoter and Practitioner: The Singapore Government's Experience,' Keynote Address by Minister of State for Trade \& Industry and National Development, at the "Singapore/UK: Developing Corporate Social Responsibility" Seminar, 23 February 2004, Singapore.

Bonini, S. M. J., Mendonca, L. T., \& Oppenhein, J. M. (2006). When social issues become strategic. The McKinsey Quarterly, 2006(2), 20-31.

Chapple, W., \& Moon, J. (2005). Corporate Social Responsibility (CSR) in Asia: a seven-country study of CSR web site reporting. Business and Society, 44(4), 415-441.

Chhabara, R. (2007). 'Open for business ethics,' Ethical Corporation (September 2007), p. 28.

Chua, B. H. (1995). Communitarian ideology and democracy in Singapore. London: Routledge.

Davis, G. F., Whitman, M. V. N., \& Zald, M. N. (2008). 'The responsibility paradox!' Stanford Social Innovation Review (Winter 2008), pp. 30-37.

Deakin, S., \& Hobbs, R. (2007). False dawn for CSR? Shifts in regulatory policy and the response of the corporate and financial sectors in Britain. Corporate Governance, 15(1), 68-76.

Deakin, S., \& Whittaker, D. H. (2007). Re-embedding the Corporation? Comparative perspectives on corporate governance, employment relations and corporate social responsibility. Corporate Governance, $15(1), 1-4$.

Foo, C. (2004). Keynote Address by Minister of State for Defense and Chairman, Spring Singapore at the launch of the National Tripartite Initiative on Corporate Social Responsibility, 26 May 2004, Singapore.

Friedman, T. (2007). 'The Green Road Less Traveled,' The New York Times, 15 July.

Frynas, J. G. (2006). Corporate social responsibility in emerging economies. Journal of Corporate Citizenship, 24, 16-19.

Hamilton-Hart, N. (2006). Singapore's climate change policy: the limits of learning. Contemporary Southeast Asia, 28(3), 363-384.

Haslam, P. A. (2007). Is corporate social responsibility a constructivist regime? Evidence from Latin America. Global Society, 21(2), 269-296.

Heng, C. H. (2005a). 'Creating sustainable outcomes with CSR,' Speech by Minister of State for Trade and Industry, at the launch of Singapore Compact, 26 January 2005, Singapore.

Heng, S. K. (2005b). 'Building Singapore as a trusted business hub,' keynote address by Managing Director, Monetary Authority of Singapore, at the Commercial Affairs Department's "Corporate Governance Conference on Corporate Ethics-Emerging Challenges and Responses," Singapore, 23 November 2005.

International Herald Tribune. (2006). 'Asians demanding greater corporate responsiveness,' 25 October.

International Herald Tribune. (2007). 'Viceroys long gone, EU grows in Asia,' 16 March.

Kao, J. (2007). Innovation nation. New York: Free Press.

Lee, K. Y. (2005). 'Ethical leadership a competitive advantage,' Address by the Minister Mentor at the Asian Strategy And Leadership Institute's "World Ethics and Integrity Forum 2005," Kuala Lumpur, 28 April 2005.

Leggett, C. (2007). From industrial relations to manpower planning: the transformation of Singapore's industrial relations. International Journal of Human Resource Management, 18(4), 642-664.

Lim, B. H. (2004). Business, ethics and labour. In F.-J. Richter \& P. C. M. Ma (Eds.), Asia's new crisis: Renewal through total ethical management (pp. 145-159). Singapore: Wiley.

Lim, B. H. (2005). Keynote address by the NTUC Secretary-General, at the NTUC-DGB seminar on 'Global Challenges and Union Response,' 11 January 2005, Singapore.

Lim-Lum, K.-W. (2004). Defining corporate social responsibility—a Singapore perspective. The Australian Journal of Asian Law, 6, 131-156.

Lyon, E. (2007). CSR law in Indonesia. CSR Asia Weekly, 3, 1-3.

Matten, D., Crane, A., \& Moon, J. (2007). Corporate responsibility for innovation: A citizenship framework. In G. Hanekamp (Ed.), Business ethics of innovation (pp. 63-87). Berlin: Springer.

McBarnet, D., Voiculescu, A., \& Campbell, T. (Eds.). (2007). The new corporate accountability: Corporate Social responsibility and the law. Cambridge: Cambridge University Press.

MEWR (Ministry of the Environment and Water Resources, Singapore). (2006). The Singapore green plan 2012 (2006th ed.). Singapore: MEWR.

Montgomery, D. B. (2005). Asian management education: some twenty-first century issues. Journal of Public Policy and Marketing, 24(1), 150-154.

Moon, J. (2002). The social responsibility of business and new governance. Government and Opposition, $37(3), 385-408$. 
Moon, J. (2004). 'Government as a driver of corporate social responsibility,' International Centre for Corporate Social Responsibility Research Paper Series no. 20-2004, Nottingham University Business School.

Nader, L. (1990). Harmony ideology: Justice and control in a Zapotec mountain village. Stanford: Stanford University Press.

Nader, L. (2002). The life of the law: Anthropological projects. Berkeley: University of California Press.

Nguyen, T. D. (2007) 'Jakarta turns off investors big-time,' Business Times (Singapore), 31 August, p. 23.

Peh, S. H. (2007). 'Pragmatic green push by "party of white",' The Straits Times, 4 May, p. 27.

People's Action Party. (1999). 'Winning over workers,' in For People, Through Action, By Party (Singapore: People's Action Party, 1999), pp. 28-37.

Richter, F.-J., \& Mar, P. C. M. (2004). Why ethics? In F.-J. Richter \& P. C. M. Ma (Eds.), Asia's new crisis: Renewal through total ethical management (pp. 3-15). Singapore: Wiley.

Singapore Compact. (2007). Our CSR journey: The Singapore experience. Singapore: Singapore Compact for Corporate Social Responsibility.

Sriramesh, K., Ng, C. W., Ting, S. T., \& Wanyin, L. (2007). Corporate social responsibility and public relations: Perceptions and practices in Singapore. In S. May, G. Cheney, \& J. Roper (Eds.), The debate over corporate social responsibility (pp. 119-134). New York: Oxford University Press.

Tan, C. H. (2007). Employment relations in Singapore (5th ed.). Singapore: Prentice Hall.

Tan, E. K. B. (2011). The state of play of CSR in Singapore. Singapore: Lien Centre for Social Innovation, Singapore Management University.

The Straits Times (Singapore). (2007a). 'Talent flow hinges on green issues,' 5 October, p. H15.

The Straits Times (Singapore). (2007b). 'For Singapore, it pays to go green,' 12 May, p. S8.

The Straits Times (Singapore) (2007c). 'Singapore to move into research on clean energy,' The Straits Times, 17 March, p. 1.

Tully, S. (Ed.). (2005). International documents on corporate responsibility. Cheltenham: Edward Elgar.

Vietor, R. H. K. (2007). How countries compete: Strategy, structure, and government in the global economy. Boston: Harvard Business School Press.

Vogel, D. (2005). The market for virtue: The potential and limits of corporate social responsibility. Washington, DC: Brookings Institution Press.

Welford, R. (2004). Corporate social responsibility in Europe and Asia: critical elements and best practice. Journal of Corporate Citizenship, 13, 31-47.

Yaacob, I. (2007). Speech by the Minister for the Environment and Water Resources, at the Global Summit for the Environment (B4E), 19 April 2007, Singapore. 